\title{
Crescimento bacteriano em perfluorocarbonos líquidos: estudo "In vitro"
}

\author{
Bacterialgrowth in perfluorocarbon liquids: an in vitro study
}

Leciana Rorato Chiconelli Vanzo ${ }^{(1)}$

Agostinho Bryk Junior (2)

Maria Claudia Gomes Komatsu ${ }^{(2)}$

Carlos Augusto Moreira Junior ${ }^{(3)}$

\section{RESUMO}

Objetivo: Verificar o crescimento de $P$. aeruginosa e $S$. aureus em perfluoroctano líquido. Métodos: Foram utilizados três meios de cultura: perfluoroctano, caldo de digestão de soja mais caseína e solução salina a $0,9 \%$. Dividiram-se $5 \mathrm{ml}$ de perfluoroctano em frascos contendo $1 \mathrm{ml}$ cada. Nos frascos 1 e 2 inoculou-se 1 colônia inteira de $P$. aeruginosa e nos recipientes 3 e 4 a mesma quantidade de $S$. aureus. O frasco 5 serviu como controle sem sofrer contaminação. Inoculou-se também 1 colônia de cada bactéria em $1 \mathrm{ml}$ dos demais meios de cultura. Colônias inteiras foram utilizadas pois o perfluoroctano é imiscível em água. As soluções foram mantidas em incubador $37^{\circ} \mathrm{C}$ por 10 dias. Em câmara de fluxo laminar foi realizado o repique utilizando-se alça calibrada 1:1000 no tempo zero, $72 \mathrm{~h}, 168 \mathrm{~h}$ e $240 \mathrm{~h}$ após a contaminação. $O$ crescimento bacteriano foi verificado por meio da contagem de colônias em placas de agar sangue $24 \mathrm{~h}$ após cada repique. Resultados: Houve crescimento de $P$. aeruginosa $\mathrm{S}$. aureus no tempo zero em todos os meios, confirmando a inoculação bacteriana. Nas horas seguintes o crescimento não mais foi observado em perfluoroctano. Ambas as bactérias desenvolveram-se abundantemente nos demais meios de cultura em todos os tempos. No frasco controle não houve crescimento bacteriano. Conclusão: Os resultados deste estudo "in vitro" demonstraram que o perfluoroctano parece não representar um meio favorável para o crescimento bacteriano.

Descritores: Perfluorocarbonetos; Crescimento bacteriano; Pseudomonas aeruginosa; Staphylococcus aureus; In vitro.
Trabalho realizado no Serviço de Oftalmologia do Hospital de Clínicas da Universidade Federal do Paraná.

Vencedor do prêmio Ciba Vision, melhor Tema Livre em segmento posterior, no XXIII Simpósio Internacional Moacyr Álvaro - III SIMAsp 2000. Apresentado em 25/02/2000, São Paulo (SP). Apresentado na "Annual meeting of the Association for Research in Vision and Ophthalmology", Fort Lauderdale, Florida, 03/05/2000.

(1) Médica Residente em Oftalmologia do Hospital de Clínicas da Universidade Federal do Paraná

(2) Acadêmicos do $5^{\circ}$ ano da Faculdade de Medicina da Universidade Federal do Paraná.

(3) Professor Titular de Oftalmologia da Universidade Federal do Paraná

Os autores declaram não possuir interesse financeiro no desenvolvimento ou marketing de qualquer instrumento ou substância referidos no estudo.

Endereço para correspondência: Maria Claudia Gomes Komatsu Rua Alferes Poli, 271 - Curitiba (PR) CEP 80230-090. E-mail: dragu@ewb.matrix.com.br

\section{INTRODUÇÃO}

Desde os primeiros relatos de uso de Perfluorocarbonos líquidos (PFCL) na cirurgia vítreo-retiniana, a partir de 1987 é cada vez mais difundido seu uso entre os cirurgiões de retina ${ }^{1-5}$.

Essas substâncias mostraram-se úteis por apresentarem propriedades físico-químicas favoráveis ao bom desempenho do ato cirúrgico ${ }^{6}$, possibilitando conforto ao cirurgião tanto na sua administração quanto na sua remoção ao final da intervenção cirúrgica. Os perfluoroquímicos líquidos são compostos pertencentes a uma classe de oligômeros do óxido de perfluoropropileno purificados. Apresentam excelente estabilidade química e térmica em virtude de suas conformações estruturais de carbono, oxigênio e flúor. Os perfluorocarbonos líquidos (PFCL) geralmente apresentam as seguintes propriedades: são imiscíveis com a água ${ }^{6-7}$, transparentes, incolores, inertes quimicamente, inodoros, não são 
inflamáveis, possuem baixa viscosidade, insolubilidade em solventes orgânicos e alta gravidade específica ${ }^{8}$.

Esses compostos são opticamente transparentes sendo seu índice de refração semelhante ao do corpo vítreo normal, ou seja, 1,29, o que permite uma fácil visualização intra-ocular durante manobras per-operatórias ${ }^{7}$.

A baixa viscosidade de 2 a 3 centistokes a $25^{\circ} \mathrm{C}^{7}$ bem como a insolubilidade em solventes orgânicos convencionais 8 representam outras propriedades favoráveis desses compostos. No entanto, não é rara a permanência de pequenas quantidades de PFCL (bolhas ou gotículas) ${ }^{9}$ dentro da cavidade vítrea após o término da cirurgia.

A permanência de uma substância estranha na cavidade vítrea poderia representar um meio de cultura para a proliferação bacteriana, ocasionando assim uma infecção grave e de tratamento complicado, pois há dificuldade de se manter concentrações terapêuticas de antibióticos na cavidade vítrea por tempo adequado ${ }^{10}$. Desta forma é importante verificar o potencial de contaminação dos PFCL. Inúmeras pesquisas demonstram que os agentes patogênicos mais comuns nas infecções intraoculares são $S$. aureus e $P$. aeruginosa ${ }^{10-14}$.

O objetivo do presente estudo foi verificar o crescimento de $S$. aureus e $P$. aeruginosa em perfluoroctano (PFO), um dos PFCL mais utilizados na cirurgia vítreo-retiniana ${ }^{6}$.

\section{MÉTODOS}

Três meios de cultura foram utilizados: PFO, caldo de digestão de soja mais caseína (TSB) e solução salina a $0,9 \%$ (SS).

Cinco $\mathrm{ml}$ de PFO foram divididos em frascos contendo $1 \mathrm{ml}$, identificados pela numeração de 1 a 5 . Nos frascos 1 e 2 inoculou-se uma colônia inteira de $P$. aeruginosa (ATCC 27853) e nos recipientes 3 e 4 a mesma quantidade de $S$. aureus (ATCC 25923). O frasco 5 serviu de controle sem sofrer contaminação. A utilização de colônias bacterianas inteiras se deve ao fato do PFO ser imiscível em água.

Com o objetivo de se verificar a viabilidade dos microorganismos, inoculou-se separadamente uma colônia de cada bactéria em frascos contendo $1 \mathrm{ml}$ de TSB, um meio de cultura rico em nutrientes favoráveis à proliferação bacteriana.

Repetiu-se o mesmo procedimento para a contaminação da solução salina a $0,9 \%$, a fim de se comparar os resultados do PFO com outro meio que não possui nutrientes.

Todas a soluções foram homogeneizadas em Vortex a 1000 rpm e, posteriormente, mantidas em incubador $37^{\circ} \mathrm{C}$ por 10 dias.

Realizou-se o repique utilizando-se uma alça calibrada de 1:1000 no tempo zero, 72 horas, 168 horas e 240 horas após a contaminação. Efetuou-se toda a manipulação do material em uma câmara de fluxo laminar a fim de evitar contaminação externa.

Verificou-se o crescimento bacteriano através da contagem de colônias em placas de agar sangue $24 \mathrm{~h}$ após cada repique.

\section{RESULTADOS}

No tempo zero observou-se o crescimento de 1 colônia e 3 colônias de $P$. aeruginosa nos frascos 1 e 2 , respectivamente. No entanto, nos demais tempos de aferição - 72h, 168h, 240h não se detectou nenhum desenvolvimento dessa bactéria em PFO. Já nos meios TSB e SS o crescimento foi abundante em todos os tempos (Tabela 1).

Constatou-se no tempo zero a presença de 01 colônia e de 16 colônias de S. aureus nas amostras 3 e 4, respectivamente. Nas horas seguintes o crescimento desse microrganismo não foi observado em PFO. Nos meios TSB e SS este microrganismo se desenvolveu abundantemente, ocorrendo uma diminuição do seu crescimento nos dois últimos tempos de aferição (Tabela 2).

No frasco 5, PFO controle não contaminado, não houve proliferação bacteriana em nenhum dos tempos.

\section{DISCUSSÃO}

Como era previsto, o maior crescimento bacteriano se deu em caldo de digestão de soja mais caseína por se tratar de um meio de cultura próprio para o desenvolvimento bacteriano.

Embora a $P$. aeruginosa seja um germe muito resistente ${ }^{8}$, capaz de se desenvolver até em meios extremamente desfavoráveis, não houve crescimento desse microrganismo em

\begin{tabular}{|c|c|c|c|c|}
\hline \multirow{2}{*}{$\begin{array}{l}\text { Meios de } \\
\text { cultura }\end{array}$} & \multicolumn{4}{|c|}{ Número de colônias } \\
\hline & Oh & $72 \mathrm{~h}$ & $168 h$ & $240 h$ \\
\hline PFO(frasco 1) & 1 & 0 & 0 & 0 \\
\hline PFO(frasco 2) & 3 & 0 & 0 & 0 \\
\hline TSB & $\begin{array}{l}\text { Abundante } \\
++++/ \text { IV }\end{array}$ & $\begin{array}{l}\text { Abundante } \\
++++/ \text { IV }\end{array}$ & $\begin{array}{l}\text { Abundante } \\
++++/ \text { IV }\end{array}$ & $\begin{array}{c}\text { Abundante } \\
+++/ \text { IV }\end{array}$ \\
\hline SS & $\begin{array}{l}\text { Abundante } \\
++++/ \text { IV }\end{array}$ & $\begin{array}{l}\text { Abundante } \\
++++/ \text { IV }\end{array}$ & $\begin{array}{l}\text { Abundante } \\
+++/ \text { IV }\end{array}$ & $\begin{array}{c}\text { Abundante } \\
+++/ \text { IV }\end{array}$ \\
\hline \multicolumn{5}{|c|}{$\begin{array}{l}\text { PFO: Perfluoroctano } \\
\text { TSB: Caldo de digestão de soja mais caseína } \\
\text { SS: Solução salina a } 0,9 \%\end{array}$} \\
\hline
\end{tabular}

Tabela 2: Quantificação do crescimento de $S$. aureus (ATCC 25923) em diferentes meios de cultura

\begin{tabular}{|c|c|c|c|c|}
\hline Meios de & & Número & de colônias & \\
\hline cultura & Oh & $72 \mathrm{~h}$ & $168 \mathrm{~h}$ & $240 \mathrm{~h}$ \\
\hline PFO (frasco 3) & & 1 & 0 & 00 \\
\hline PFO (frasco 4) & & 16 & 0 & 00 \\
\hline TSB & $\begin{array}{c}\text { Abundante } \\
++++/ \text { IV }\end{array}$ & $\begin{array}{c}\text { Abundante } \\
++++/ \text { IV }\end{array}$ & $\begin{array}{c}\text { Abundante } \\
++++/ \text { IV }\end{array}$ & $\begin{array}{c}\text { Abundante } \\
+++/ \text { IV }\end{array}$ \\
\hline SS & $\begin{array}{l}\text { Abundante } \\
++++/ \text { IV }\end{array}$ & $\begin{array}{l}\text { Abundante } \\
++++/ \text { IV }\end{array}$ & $\begin{array}{c}\text { Abundante } \\
+++/ \text { IV }\end{array}$ & $\begin{array}{c}\text { Abundante } \\
++/ \text { IV }\end{array}$ \\
\hline
\end{tabular}


nenhuma das amostras de PFO em estudo, com exceção daquelas do tempo zero, que correspondem ao momento da inoculação do germe. Somente a falta de nutrientes não explicaria adequadamente a ausência de crescimento dessa bactéria, porque demonstramos que mesmo em solução salina a $0,9 \%$ essa cresceu abundantemente.

Não houve crescimento de $S$. aureus em PFO, exceto no tempo zero em que o germe foi inoculado. Em solução salina a $0,9 \%$, o desenvolvimento do estafilococo foi abundante, no entanto houve um pequeno decréscimo a partir de 168 horas (7dias).

$\mathrm{Na}$ amostra de PFO utilizada como controle não contaminado, não ocorreu proliferação de nenhuma bactéria, demonstrando que o PFO em uso era um produto estéril além de não ter ocorrido contaminação externa durante a manipulação da substância.

\section{CONCLUSÃO}

Os resultados deste estudo "in vitro" demonstraram que o PFO parece não representar um meio favorável para o crescimento bacteriano.

\section{ABSTRACT}

Purpose: To determine the growth of $\mathrm{P}$. aeruginosa and $\mathrm{S}$. aureus in liquid perfluoroctane perfluoroctane. Methods: Three culture media were used: perfluoroctane, soy and casein digestion broth and $0.9 \%$ saline. Five $\mathrm{ml}$ perfluoroctane were distributed among $1 \mathrm{ml}$ flasks. Flasks 1 and 2 were inoculated with 1 entire colony of $\mathrm{P}$. aeruginosa and flasks 3 and 4 were inoculated with the same amount of $\mathrm{S}$. aureus. Flask 5 served as control without any contamination. One colony of each bacterium was also inoculated in $1 \mathrm{ml}$ of the remaining culture media. Entire colonies were used because perfluoroctane is immiscible with water. All solutions were kept in an incubator at $37^{\circ} \mathrm{C}$ for 10 days. The cultures were replated under a laminar flow hood using a calibrated 1:1000 loop at times zero, $72 \mathrm{~h}, 168 \mathrm{~h}$ and $240 \mathrm{~h}$ after contamination. Bacterial growth was determined by counting the colonies on blood agar plates 24 hours after each replating. Results: Time zero demonstrated bacterial growth in all media, confirming inoculation. During the subsequent hours no further growth of these microorganisms was observed in perfluoroctane. Both bacteria developed abundantly in the remaining culture media at all times studied. The control flask did not show any bacterial growth. Conclusions: The "in vitro" results show that PFO does not seem to represent a favorable medium for bacterial growth.

Keywords: Perfluorocarbons; Bacterial growth; Pseudomonas aeruginosa; Staphylococcus aureus; In vitro.

\section{REFERÊNCIAS}

1. Chang S, Zimmerman NJ, Iwamoto T, Ortiz R, Faris D. Experimental vitreous replacement with perfluorotributylamine. Am J Ophthalmol 1987;103:29-37.

2. Chang S. Low viscosity liquid fluorochemicals in vitreous surgery. Am J Ophthalmol 1987;103:38-43.

3. Chang S, Ozmert E, Zimmerman NJ. Intraoperative perfluorocarbon liquids in the management of proliferative vitreoretinopathy. Am J Ophthalmol 1987;106: 668-74

4. Chang S, Reppucci V, Zimmerman NJ, Heinemann MH, Coleman DJ. Perfluorocarbon liquids in the management of traumatic retinal detachments. Ophthalmology 1989;96:785-91.

5. Coll GE, Chang S, Sun J, Wieland MR, Berrocal MH. Perfluorocarbon liquid in the management of retinal detachment with proliferative vitreoretinopathy. Ophthalmology 1995;102:630-8.

6. Bourke RD, Simpson RN, Cooling RJ, Sparrow JR. The stability of perfluoroN-octane during vitreoretinal procedures. Arch Ophthalmol 1996;114:537-44.

7. Fernandes EG. Perfluorocarbono líquido: introdução de um novo conceito na cirurgia vítreo-retiniana. Arq Inst Penido Burnier 1994;36:8-11.

8. Moreira Jr CA. Uso de perfluorocarbonos líquidos na cirurgia vitreo-retiniana. In: Freitas J A H. Vitrectomia. Rio de Janeiro: RioMedi; 1994. p. 25-30.

9. Moreira Jr CA, Moreira ATR, Moreira H. Perfluorocarbonos líquidos na cirurgia vitreo-retiniana: experiência de 5 anos. Rev Bras Oftalmol 1992;52:59-62.

10. Moreira Jr CA, Moreira AT, Bonomo PPO, Liggett PE, Trousdale MD. Hialuronato de sódio como veículo para gentamicina intraocular: estudo "in vitro". Rev Bras Oftalmol 1990;49:13-20.

11. Brinton GS, Topping TM, Hyndiuk RA, Aaberg TM, Reeser FH, Abrams GW. Post traumatic endophthalmitis. Arch Ophthalmol 1984;102:547-50.

12. Forster RK. Etiology and diagnosis of bacterial postoperative endophthalmitis. Ophthalmology 1978;85:320-6.

13. Jaffe NS. Cataract surgery and its complications. 3rd ed. St. Louis: Mosby; 1981. p. 431-63.

14. Yasuda N, Suzanna Jr R, Yanaguita R, Silva L. Infecção intraocular experimental por Staphylococcus epidermidis. Rev Bras Oftalmol 1975;34:431-3.

\section{Congresso Sul Brasileiro de Oftalmologia XI Simpósio da Sociedade Catarinense de Oftalmologia I Simpósio Regional Sul da Sociedade Brasileira de Plástica Ocular 30 e 31 de Março de 2.001 COSTÃO DO SANTINHO RESORT - FLORIANÓPOLIS - SC} INFORMAÇÕES: Fax : (48) 239-4130 e-mail: ivan.coelho@fsb.zzn.com / icoi|@usa.net 